\section{The clinical validity of the treatment satisfaction survey for intraocular pressure in ocular hypertensive and glaucoma patients}

DG Day ${ }^{1}$, ED Sharpe 2 , MJ Atkinson ${ }^{3}$, JA Stewart ${ }^{4}$ and WC Stewart ${ }^{4,5}$

\begin{abstract}
Purpose To provide initial validation of the Treatment Satisfaction Survey-Intraocular Pressure (TSS-IOP) quality-of-life survey that analyses specific issues related to side effects, patient satisfaction, and compliance.

Methods A prospective, observational cohort of 250 consecutive patients with primary openangle glaucoma or ocular hypertension was administered the TSS-IOP survey.

Results Factors that correlated with patient satisfaction included perceived effectiveness of the medicine $(F=7.47, P<0.001)$, ocular irritation $(F=6.06, P<0.001)$, conjunctival hyperaemia $(F=4.40, P<0.001)$, ease of use ( $F=8.52, P<0.001)$, and convenience of use $(F=6.90, P<0.001)$. Patient compliance, acceptance of their illness, and knowledge of glaucoma were also related to perceived effectiveness of the medicine $(P<0.001)$, ease of use $(P<0.05)$ and convenience $(P<0.001)$. Physician ratings of patient pressure control, side effects, and instillation problems also were significantly correlated to patient satisfaction $(R=0.13-0.26, P=0.05-0.001)$. The physician ratings of patient compliance, however, were not significantly related to any dimension of patient satisfaction $(P>0.05)$. Among monotherapy prostaglandin treatments, latanoprost demonstrated statistically greater satisfaction than bimatoprost or travoprost regarding conjunctival hyperaemia $(P<0.05)$ and eye irritation $(P<0.01)$.

Conclusions This study provides initial evidence that patient satisfaction may be related to compliance, perceived effectiveness of treatment, adverse side effects, ease and
\end{abstract}

convenience of use, acceptance of illness, and knowledge of glaucoma.

Eye (2006) 20, 583-590. doi:10.1038/sj.eye.6701932; published online 3 June 2005

Keywords: glaucoma; satisfaction; compliance; treatment effectiveness; convenience

\section{Introduction}

Over the past several years, a number of new medications have become available to treat ocular hypertension and primary open-angle glaucoma. In general, these medications have increased efficacy, reduced side effects, and enhanced dosing convenience compared to many of the older products. With the improved quality of medications recent research has concentrated more on supplemental details of therapy, such as the medicine's impact on the patient's quality of life. Accordingly, several validated surveys have been developed over the past several years that evaluate the impact of glaucoma on a patient's activities of daily living and vision. ${ }^{1-9}$

Further, several years ago Laibovitz et $a l^{10}$ validated the Comparison of Ophthalmic Medications for Quality of Life questionnaire (COMQoL), which was designed to compare specifically the tolerability of ophthalmic medications and to evaluate the effect of ocular hypotensive therapy on side effects, routine living activities, quality of life, compliance, and patient satisfaction with medication. The data were used to show an increased preference for dorzolamide compared to pilocarpine due to reasons of side effects and patient satisfaction. ${ }^{11}$ This earlier questionnaire does not consider,
${ }^{1}$ Atlanta Research Company, Atlanta, GA, USA

${ }^{2}$ Charleston Research Company, Charleston, SC, USA

${ }^{3}$ Pfizer, Inc., Worldwide Outcomes Research, San Diego, CA, USA

${ }^{4}$ Pharmaceutical Research Network, LLC, Charleston, SC, USA

${ }^{5}$ Carolina Eye Institute at the University of South Carolina School of Medicine, Columbia, SC, USA

Correspondence

WC Stewart,

Pharmaceutical Research Network, LLC, 1 Southpark Circle, Suite 110

Charleston, SC 29407, USA

Tel: + 1843762 6500;

Fax: + 18437627444 .

E-mail: info@prnorb.com

Received: 16 December 2004

Accepted in revised form:

12 April 2005

Published online:

3 June 2005 
however, patient knowledge and perception of treatment, ease and convenience of use, as well as side effects that became apparent with the availability of prostaglandin analogs in 1996.

The purpose of this article is to describe the clinical results among commonly used glaucoma products from an initial validation study with a new instrument, the Treatment Satisfaction Survey-Intraocular Pressure (TSS-IOP). The survey focuses on patient satisfaction and perception of their glaucoma medication and the ability of these factors to predict patient compliance.

\section{Materials and methods}

\section{Treatment Satisfaction Survey-Intraocular Pressure}

The TSS-IOP questionnaire is a patient reported outcome measure designed to assess patient satisfaction with various attributes associated with topical ocular medications to control intraocular pressure. Specialists in internal medicine and medical outcomes research outlined the content or attributes in the first stages of the validation process. The ophthalmic content was developed by a research team in collaboration with 32 patients participating in one of four 90-min focus groups, in which patients were encouraged to describe their own experiences with treatment. Patient input was used to develop and refine an initial pool of 45 questions that would be subject to psychometric testing in this current study (the second stage of the validation process). The psychometric portion of this current study (using the supplemental question survey) was used to select the final items or questions for the final TSS-IOP questionnaire and to examine the performance of the new treatment satisfaction rating scales on clinically important aspects of the patient's treatment experience (Table 1). ${ }^{12}$

The validation study portion of this study is presented elsewhere and follows the generally accepted guidelines for the psychometric validation of patient reported outcome instruments. ${ }^{12}$ This included the examination of factorial construct validity and internal consistency of resulting scales, as well as the assessment of the clinical criterion and convergent validity of the instrument. ${ }^{12}$ As a result of the above-described validation process, the TSS-IOP survey was found to be a valid measure of patient tolerability of medicine in glaucoma. ${ }^{12}$

The TSS-IOP survey is owned by Pfizer, Inc. Inquiries about the public use of this instrument should be made to mark.j.atkinson@pfizer.com.

\section{Patients}

The sample consisted of consecutive recruited patients with primary open-angle or ocular hypertension from the

Table 1 Validated TSS-IOP questions*

\begin{tabular}{ll}
\hline $\begin{array}{l}\text { Effectiveness } \\
1 .\end{array}$ & How satisfied or dissatisfied are you that the eye drops are preventing future vision problems? \\
$\begin{array}{c}\text { Side effects } \\
3 .\end{array}$ & How satisfied or dissatisfied are you that the eye drops are reducing current vision problems? \\
4. & How much are you bothered by prolonged burning or stinging as a result of using your eye drops? \\
5. & How much are you bothered by grittiness or sandiness in your eyes as a result of using your eye drops? \\
6. & How much are you bothered by unpleasant feelings of stickiness or crustiness in or around your eyes due to \\
Eye appearance & using your eye drops? \\
7. & How much are you bothered by dry eyes due to using your eye drops? \\
8. & Hour eye drops? \\
9. & How self-conscious have you been of eye redness caused by your eye drops? \\
Convenience of use & caused by your eye drops? \\
10. & How satisfied or dissatisfied are you with the number of times per day you are required to use your eye \\
11. & drops? \\
12. & How satisfied or dissatisfied are you with the time of day that you are required to use your eye drops? \\
Ease of administration & \\
13. & How easy or difficult is it to remember to use your eye drops at the time of day it should be used? \\
14. & applying too much medication? \\
15. & When standing up, how easy or difficult is it to correctly angle your head to accurately apply the eye drops? \\
& How confident are you in your ability to consistently get exactly the right amount of eye drop medication \\
\hline
\end{tabular}

*Items were scaled on either a five-or seven-point scale on the dimension being assessed. For example, from 'Extremely Satisfied' to 'Extremely Dissatisfied' for satisfaction items or 'Extremely Bothered' to 'Not Bothered' for the impact of side effects questions. 
outpatient clinics of two of the authors (DGD, EDS) who agreed to participate and met the inclusion and exclusion criteria. The design was a prospective, observational cohort.

Patients included in this study were 18 years of age or older, willing to comply with the investigator's and protocol's instructions, signed the Institutional Review Board approved informed consent document, had a clinical diagnosis of primary open-angle or ocular hypertension (as defined by AAO diagnostic codes) in at least one eye, currently treated with a marketed glaucoma ophthalmic drop medication in at least one eye for at least 30 days prior to Visit 1, and had adequate visual acuity and mental ability to read and understand English.

Patients who had any clinically significant, serious, or severe medical or psychiatric condition, participated in any investigational ophthalmic drug or device trial within the previous 30 days prior to Visit 1, previously participated in this protocol, were unable to understand the trial procedures, and thus unable to give informed consent, and had intraocular conventional or laser surgery within the past 2 months in the eye(s) treated with glaucoma medication were excluded from this study.

\section{Procedures}

Patients signed an Institutional Review Board approved informed consent document before any procedures were performed. Patients then had their medical and ocular history taken, including ocular and systemic medications, and patients completed a supplemental questionnaire to the TSS-IOP concerning their medical therapy expectations (Table 2). Afterwards, patients filled out the TSS-IOP questionnaire itself. Patients then received a clinical examination as part of their routine glaucoma care. At the end of the visit, the physician completed a questionnaire regarding their assessment of the patients' treatment, tolerability of the medicine, and compliance. Patients were asked about their reluctance to use their medication.

A small sample of 25 patients was asked to return for a second visit to complete the TSS-IOP questionnaire again to quantify test-retest reliability. Patients were seen approximately 1 week after their initial visit. During this time any changes in medical or ophthalmic history as well as concomitant medications were recorded. Patients then completed the TSS-IOP questionnaire in the same way as the first visit.

Table 2 TSS-IOP supplemental questionnaire

(Multiple choice answers were provided, but are not supplied in this table)

1. Employment status?

2. How long have you had glaucoma?

3. When do you take your eye drop medication(s)?

4. Overall how well does your eye medication(s) work?

5. How knowledgeable are you about glaucoma and its treatment?

6. Do you wear contact lenses?

7. Please rate how much difficulty you have when self-administering your eye medication(s)

8. How often do you require assistance from others when using your eye medication(s)?

9. Please rate how frequently you miss the eye when administering your medication(s)

10. Please rate how frequently blinking in anticipation causes you problems when administering your eye medication(s)

11. Please rate how frequently you have trouble getting the angle of your head correct when administering your eye medication(s)

12. How frequently do you miss your eye when taking your medication(s)?

13. Please rate how frequently you mistakenly administer multiple drops when using your medication(s)

14. How often do you forget to take your eye medication(s) as it is prescribed each day?

15. When it comes to my eye medication(s) use, my concern about my future vision is the strongest motivation

16. I have come to accept and live with my eye condition

17. I am confident that I will eventually get off the glaucoma medication(s) I am using

18. I must admit, once in a while I have resisted using my eye medication(s)

19. The only way I can tell if my eye medication(s) is working is to talk with my physician or nurse

20. How likely are you to continue on your current eye medication(s) given how it is working for you?

21. How likely are you to request a change in your eye medication(s) due to current side effects?

22. To what degree have side effects influenced your decision to miss doses or stop taking your eye medication(s) as prescribed?

23. How likely are you to request a change in your eye medication(s) due to its inconvenience of use?

24. Based on your overall experiences with your eye medication(s), how likely are you to request a change to your medication(s)?

25. Please distribute 10 points among efficacy, side effects, and convenience/ease of use, to indicate how much each will affect your overall satisfaction with your current eye medication(s)

26. Please distribute 10 points among efficacy, side effects, and convenience/ease of use, to indicate how much each affects you continuing to use the eye drops as they have been prescribed

27. Please distribute 10 points among efficacy, side effects, and convenience/ease of use, to indicate how much each affects whether you will request a change in your eye medication(s) 
At each visit, patients were provided adequate time to read and complete the questionnaire. Staff assistance was available to assist with the questionnaire if needed. All questions had to be answered before the questionnaire was considered complete.

\section{Statistical methods}

This paper reports on the relationship between patientreported treatment satisfaction and clinically important aspects of the treatment experience. The planned analyses, which are standard for early instrument validation, were the following: descriptive statistics were used to show the demographic and clinical characteristics of the sample. A series of five forward stepwise regression analyses were used to examine the associations between each of the five TSS-IOP scales as dependent measures and clinical, patient attitudinal and demographic characteristics as independent variables. A series of exploratory nonparametric correlation analyses were conducted to examine the magnitude of the observed relationships. Finally, an ANCOVA analysis was used to explore whether the group differences in treatment satisfaction existed by IOP medication type, while controlling for physician-rated effectiveness of intraocular pressure control. Physician rated adequacy of patient satisfaction was used as a covariant to control for potential differences of the effects of disease severity across treatment groups. No post hoc analyses were performed.

\section{Results}

\section{Patients}

The recorded age, race, gender, glaucoma diagnosis, iris colour, employment, and number of medications are shown in Table 3. Of the 412 patients approached to complete the 31-item TSS-IOP questionnaire, 252 patients consented, and 250 provided complete data sets $(60.7 \%)$. Patients who declined did so due to time constraints $(n=91)$, inability to read the survey due to routine pupil dilation $(n=39)$, or because the requested information was considered too personal $(n=32)$.

\section{Prediction of patient satisfaction}

Table 4 presents the results of five regression models used to explore clinical and patient characteristics associated with the five satisfaction scales on the TSS-IOP questionnaire. Significant correlates of patient satisfaction included the effectiveness of the medicine, ocular irritation, conjunctival hyperaemia, and ease as well as convenience of use.
Table 3 Patient characteristics

\begin{tabular}{|c|c|c|}
\hline & & $n(\%)$ \\
\hline Age (years) & $64.6 \pm 13.1$ & \\
\hline History of elevated IOP (years) & $8.4 \pm 7.8$ & \\
\hline \multicolumn{3}{|l|}{ Gender } \\
\hline Females & & $141(56.4)$ \\
\hline Males & & $109(43.6)$ \\
\hline \multicolumn{3}{|l|}{ Race } \\
\hline Caucasian & & $138(55.2)$ \\
\hline African American & & 109 (43.6) \\
\hline Hispanic & & $3(1.2)$ \\
\hline \multicolumn{3}{|l|}{ Iris color } \\
\hline Brown & & $142(56.8)$ \\
\hline Blue & & $67(26.8)$ \\
\hline Other & & $41(16.4)$ \\
\hline \multicolumn{3}{|l|}{ Employment } \\
\hline Retired & & $134(53.6)$ \\
\hline Full or part-time & & $99(39.6)$ \\
\hline Unemployed & & $17(6.8)$ \\
\hline \multicolumn{3}{|l|}{ Number of medications } \\
\hline \multicolumn{3}{|l|}{ Monotherapy $(n=148)$} \\
\hline Beta-blockers & & $34(23.0)$ \\
\hline Prostaglandin analogues & & $80(54.0)$ \\
\hline CAI & & $22(15.0)$ \\
\hline Alpha-agonists & & $12(8.0)$ \\
\hline \multicolumn{3}{|l|}{ Adjunctive therapy $(n=102)$} \\
\hline Beta-blockers & & $48(22.0)$ \\
\hline Prostaglandin analogues & & $85(39.0)$ \\
\hline CAI & & $49(22.0)$ \\
\hline Alpha-agonists & & $31(14.0)$ \\
\hline
\end{tabular}

$\mathrm{CAI}=$ carbonic anhydrase inhibitors $\mathrm{IOP}=$ intraocular pressure.

\section{Compliance}

The patient's reluctance to use medications correlated significantly on the TSS-IOP questionnaire with the perceived effectiveness of the medication $(P<0.001)$ and factors regarding its ease of use $(P<0.05)$ and convenience of use $(P<0.001)$ (Table 5). Further, the patient's acceptance of their illness and their knowledge about glaucoma itself was correlated to these three satisfaction criteria (Table 5).

\section{Treatment satisfaction and dosing frequency}

Patients who were prescribed a single medication $(n=151)$ showed statistically greater satisfaction than those patients on multiple medicines $(n=99)$ with several parameters of the TSS-IOP questionnaire including side effects and eye irritation (93.4 (12.7) vs 88.7 (15.2), $P=0.01$; 93.4 (11.1) vs 87.5 (17.8), $P=0.001$, respectively), as well as convenience of use and 
Table 4 Patients' clinical, demographic, and attitudinal predictors of regression on each of the five dimensions of patient satisfaction with treatment

\begin{tabular}{|c|c|c|c|c|c|}
\hline & \multicolumn{5}{|c|}{ (statistically significant standardized beta weights $\mathrm{P}<0.05$ ) } \\
\hline & Effectiveness & Irritation & Hyperaemia & Ease of use & Convenience of use \\
\hline \multicolumn{6}{|l|}{ Clinical predictors } \\
\hline Control of symptoms & 0.13 & & & & \\
\hline Severity of side effects & & -0.12 & & & \\
\hline Administration problems & & & & -0.13 & \\
\hline Cormorbid conditions & 0.14 & & & & 0.12 \\
\hline Combination therapy & -0.15 & -0.19 & -0.12 & & -0.19 \\
\hline \multicolumn{6}{|l|}{ Demographic predictors } \\
\hline Age & & & 0.14 & 0.10 & \\
\hline Race & 0.12 & & & & 0.12 \\
\hline Iris & & & & 0.18 & \\
\hline \multicolumn{6}{|l|}{ Attitudinal predictors } \\
\hline Glaucoma knowledge & & & 0.14 & -0.23 & -0.11 \\
\hline Medicine resistance & 0.28 & 0.12 & 0.12 & & 0.22 \\
\hline Illness acceptance & -0.15 & & & & -0.16 \\
\hline Model variance & $16 \%$ & $7 \%$ & $7 \%$ & $12 \%$ & $15 \%$ \\
\hline Significance of model & $\mathrm{F}(6)=7.47$ & $\mathrm{~F}(3)=6.05$ & $\mathrm{~F}(4)=4.40$ & $\mathrm{~F}(4)=8.52$ & $F(6)=6.90$ \\
\hline$P$-values & $<0.001$ & $<0.001$ & $<0.01$ & $<0.001$ & $<0.001$ \\
\hline
\end{tabular}

Table 5 Correlations between patient ratings on attitudinal questions and ratings on dimensions of treatment satisfaction (Spearman's rho correlations)

\begin{tabular}{lccc}
\hline Patient ratings & $\begin{array}{c}\text { Resistance to } \\
\text { using } \\
\text { medication }\end{array}$ & $\begin{array}{c}\text { Acceptance } \\
\text { of illness }\end{array}$ & $\begin{array}{c}\text { Degree of } \\
\text { knowledge } \\
\text { about glaucoma }\end{array}$ \\
\hline Effectiveness & $-0.29^{\mathrm{a}}$ & $0.27^{\mathrm{a}}$ & $0.18^{\mathrm{b}}$ \\
Eye irritation & -0.07 & 0.08 & 0.08 \\
Hyperaemia & -0.09 & 0.05 & 0.06 \\
Ease of use & $-0.15^{\mathrm{c}}$ & $0.22^{\mathrm{a}}$ & $0.24^{\mathrm{a}}$ \\
Convenience of use & $-0.24^{\mathrm{a}}$ & $0.27^{\mathrm{a}}$ & $0.21^{\mathrm{a}}$ \\
\hline
\end{tabular}

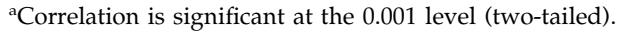

${ }^{\mathrm{b}}$ Correlation is significant at the 0.01 level (two-tailed).

${ }^{\mathrm{c}}$ Correlation is significant at the 0.05 level (two-tailed).

effectiveness scale (82.5 (14.2) vs 77.1 (16.8), $P=0.007$;

79.1 (15.4) vs 73.7 (18.0), $P=0.014$, respectively).

Further, there were significantly lower satisfaction ratings on the convenience of use scale among patients using their medications both morning and evening compared to once a day either in the morning or evening (78.3 (14.2) vs 89.6 (12.5) vs 83.8 (13.4), $P=0.02$ ) and the (perceived) effectiveness scale (83.8 (12.7) vs 81.1 (13.8) vs 74.9 (17.4), $P=0.008$ ).

\section{Correlation between physician and patient satisfaction ratings}

Physician ratings of patient treatment regarding intraocular pressure control, severity of side effects and
Table 6 Correlation between physician ratings of medicationrelated concerns and patient-satisfaction ratings

\begin{tabular}{lcccc}
\hline Patient ratings & \multicolumn{4}{c}{ Physician ratings } \\
\cline { 2 - 5 } & $\begin{array}{c}\text { Degree } \\
\text { of IOP } \\
\text { control }\end{array}$ & $\begin{array}{c}\text { Severity } \\
\text { of Side } \\
\text { effects }\end{array}$ & $\begin{array}{c}\text { Compliance } \\
\text { with medicine } \\
\text { regimen }\end{array}$ & $\begin{array}{c}\text { Problems } \\
\text { with self- } \\
\text { administration }\end{array}$ \\
\hline Effectiveness & $0.26^{\mathrm{a}}$ & $-0.16^{\mathrm{b}}$ & 0.03 & -0.09 \\
Eye irritation & 0.08 & $-0.22^{\mathrm{a}}$ & 0.10 & -0.11 \\
Hyperaemia & 0.11 & $-0.18^{\mathrm{c}}$ & 0.01 & $-0.16^{\mathrm{b}}$ \\
$\begin{array}{l}\text { Ease of use } \\
\text { Convenience of }\end{array}$ & 0.07 & -0.08 & 0.04 & $-0.13^{\mathrm{b}}$ \\
use & $0.18^{\mathrm{a}}$ & -0.05 & 0.06 & $-0.16^{\mathrm{b}}$ \\
\hline
\end{tabular}

${ }^{\mathrm{a}}$ Correlation is significant at the 0.001 level (two-tailed).

${ }^{\mathrm{b}}$ Correlation is significant at the 0.05 level (two-tailed).

CCorrelation is significant at the 0.01 level (two-tailed).

$\mathrm{IOP}=$ intraocular pressure.

instillation problems were significantly correlated with patient satisfaction ratings on the TSS-IOP questionnaire $(P<0.05)$. Nonetheless, the physician ratings of patient compliance were not significantly related to any dimension of patient satisfaction $(P>0.05)$ (Table 6).

\section{Differences among specific glaucoma medications}

Among monotherapy treatments, beta-blockers $(n=34)$ and prostaglandin analogs $(n=80)$ reported the highest satisfaction levels with convenience, followed by 
Table 7 Differences among specific glaucoma medications after controlling for physician-rated degree of IOP control

\begin{tabular}{lccccc}
\hline Patient ratings & $\begin{array}{c}\text { Travoprost } \\
\mathrm{n}=11\end{array}$ & $\begin{array}{c}\text { Bimatoprost } \\
\mathrm{n}=32\end{array}$ & $\begin{array}{c}\text { Latanoprost } \\
\mathrm{n}=113\end{array}$ & F-values & P-values \\
\hline Effectiveness & $78.0(13.6)$ & $72.6(16.6)$ & $77.9(17.9)$ & $0.67(2)$ & 0.51 \\
Eye irritation & $82.4(21.8)$ & $86.3(18.5)$ & $92.4(12.0)$ & 3.67 & 0.028 \\
Hyperemia & $78.0(35.4)$ & $83.6(25.8)$ & $91.8(14.9)$ & 3.27 & 0.041 \\
Ease of use & $66.4(29.4)$ & $67.5(20.3)$ & $69.4(20.9)$ & 0.17 & 0.84 \\
Convenience of use & $78.3(26.5)$ & $79.3(13.6)$ & $80.9(16.0)$ & 0.11 & 0.90 \\
\hline
\end{tabular}

$\mathrm{IOP}=$ intraocular pressure.

carbonic anhydrase inhibitors $(n=22)$ and alpha-agonists $(n=12)$ (85.3 (14.5), 83.6 (14.0), 79.3 (14.3) and 73.6 (11.1), respectively, $P=0.05)$. Beta-blockers reported the highest satisfaction with hyperaemia, followed by carbonic anhydrase inhibitors, prostaglandins, and alpha-agonists (99.3 (3.2), 93.6 (8.1), 90.7 (17.8) and 88.2 (27.2), respectively, $P=0.04$ ).

Among the prostaglandin analogues specifically, travoprost $(n=11)$ and bimatoprost $(n=33)$ reported a higher level of eye irritation $(F(2)=4.83, P=0.009)$ and conjunctival hyperaemia $(F(2)=3.97, P=0.021)$ than latanoprost $(n=113)$. The TSS-IOP dimensions of eye irritation and conjunctival hyperaemia differed most between medication groups after controlling for physician-rated degree of medication effectiveness (Table 7).

\section{Discussion}

The purpose of this article is to describe the initial clinical results from a validation study with a new instrument, the TSS-IOP. The survey focuses on patient satisfaction and perception of their glaucoma medication and the ability of these factors to predict patient compliance.

This study showed that patient satisfaction was statistically correlated with the perceived effectiveness of the medication, ocular irritation, conjunctival hyperaemia, and ease as well as convenience of use. The findings for ease and convenience of use as well as perceived effectiveness related to patient satisfaction are new to our knowledge. However, our data are consistent with the previous study by Laibovitz and coworkers ${ }^{10}$ which showed that ocular side effects were significantly negatively correlated with patient satisfaction. Laibovitz noted that pilocarpine was significantly more associated with vision change, accommodation difficulties and brow ache in the survey than dorzolamide. ${ }^{10}$ Further, in this current study, data regarding ocular irritation and hyperaemia were the strongest correlations found with the survey. The two side effects that were most correlated to satisfaction (eye irritation and conjunctival hyperaemia) were different in our study compared to the
Laibovitz trial, which may reflect changes in treatment patterns for glaucoma over the past decade. ${ }^{10}$

Regarding self-reported compliance to their medicine(s), patients reported that increased reluctance to use their medication negatively correlated with its perceived effectiveness as well as its ease of use and convenience. These three factors were also positively correlated to patient satisfaction. These data suggest, therefore, that patient compliance may diminish as the satisfaction with their medication decreases.

Patient's acceptance of their illness and the degree of knowledge about glaucoma (as defined in the supplemental questionnaire (Table 2, question 5)) were also related to the perceived effectiveness and ease as well as convenience of use of the medication. The idea that a patient's acceptance of their illness would be less with greater inconvenience of use would appear reasonable. However, the reason why patients with a lower level of knowledge about glaucoma would be less satisfied with a medication is not clear by our results. Perhaps the absence of sufficient information about glaucoma, and the importance of treatment, would allow a subjective sense of denial and inconvenience to overcome the patient's dedication to use the medicine appropriately.

Patients were also more satisfied instilling only one medication. This was in part due to the increased ocular irritation associated with dosing more medication. However, the greater satisfaction with a single medication was also related to greater convenience of use from instilling fewer dosages per day. This finding is consistent with Kass and coworkers ${ }^{13,14}$ and Granström and coworkers ${ }^{15}$ data on poor compliance with three or four times daily dosing compared to twice daily dosing.

Further, patients were more satisfied with once compared to twice a day therapy. This corresponds to a recent survey in Europe, which indicated that both patients $(n=250)$ and physicians $(n=250)$ were happier with once a day $v$ s twice a day therapy. In addition, the physicians, but not the patients, thought that once a day therapy increased compliance. ${ }^{16}$ There is little objective information available, however, that indicates once a day 
therapy increases compliance compared to twice a day therapy, despite the noted increase in patient satisfaction. Further, a patient's report of adequate compliance may not be quantitatively accurate. ${ }^{14,17}$ This survey attempted only to capture factors associated with noncompliance qualitatively and not quantitatively.

The physician ratings of the patient's treatment with the medication (ie, intraocular pressure control, side effect severity, and problems with instillation) were correlated to the patient's own satisfaction ratings. This is important because it shows that a physician may be able to assess patient happiness with their medication. Unfortunately, the physician ratings of patient compliance were not significantly correlated with the patient's own ranking of compliance. Consequently, by this survey the physician could only poorly predict the patient's report of compliance. This is consistent with data found by Kass and coworkers ${ }^{17}$

Regarding satisfaction among individual monotherapy medications, beta-blockers reported the highest satisfaction with conjunctival hyperaemia. Overall, the prostaglandin analogs and beta-blockers received the highest satisfaction levels, followed by carbonic anhydrase inhibitors and alpha-agonists. Of the prostaglandin analogues, latanoprost scored significantly better with conjunctival hyperaemia and ocular irritation than bimatoprost or travoprost. In regulatory trials, bimatoprost $(45 \%)$ has been previously shown to cause more conjunctival hyperaemia than latanoprost $(5-15 \%) .{ }^{18-21}$ In direct comparative trials, Stewart and coworkers $^{22}$ and Parrish and coworkers ${ }^{23}$ found significantly greater conjunctival hyperaemia in normal subjects and primary open-angle glaucoma patients with travoprost and bimatoprost. The ocular irritation finding in this survey appears to be new and not to have been noted as different among the prostaglandins in previous clinical trials. ${ }^{23-26}$

This study suggests that patient satisfaction may be related to compliance, perceived effectiveness of the treatment, ease and convenience of use, acceptance of illness, and knowledge of glaucoma, as well as side effects. Although physicians may correctly assess patient satisfaction, they may not be able to predict patient compliance.

Since the results of this trial were part of a validation process for the TSS-IOP, the clinical analyses were performed on available patients that were already scheduled for clinic. This led to an imbalance in the number of patients on various medications. Therefore, the clinical results between medications found in this report using the TSS-IOP need to be further evaluated in a prospective, randomised, double-masked analysis. In addition, the reports of patient compliance in this current study were not confirmed by independent quantitative methods. More research is needed generally to fully understand patient satisfaction and compliance with glaucoma medicines.

\section{Acknowledgements}

This study was supported by Pfizer, Inc. The TSS-IOP survey is owned by Pfizer, Inc. Inquiries about the public use of this instrument should be made to mark.j.atkinson@pfizer.com.

\section{References}

1 Guyatt GH, Feeny DH, Patrick DL. Measuring healthrelated quality of life. Ann Intenr Med 1993; 118: 622-629.

2 Hays RD, Anderson R, Revicki D. Psychometric considerations in evaluating health-related quality of life measures. Qual Life Res 1993; 2: 441-449.

3 Ware J, Hays RD. Methods for measuring patient satisfaction with specific medical encounters. Med Care 1988; 26: 393-402.

4 Jampel HD, Friedman DS, Quigley H, Miller R. Correlation of the binocular visual field with patient assessment of vision. Invest Ophthalmol Vis Sci 2002; 43: 1059-1067.

5 Montemayer F, Sibley LM, Courtright P, Mikelberg FS. Contribution of multiple glaucoma medications to visual function and quality of life in patients with glaucoma. Can J Ophthalmol 2001; 36: 385-390.

6 Mangione CM, Lee PP, Gutierrez P, Spitzer K, Berry S, Hays RD. NEI-VFQ field test investigators. Development of the 25-item Nation eye institute visual functional questionnaire. Arch Ophthalmol 2001; 119: 1050-1058.

7 Baudouin C, Bechetoille A, Bron A, Denis P, Nordmann JP, Renard JP et al. Relevance of quality of life and treatment compliance measurement in patients with chronic openangle glaucoma. J Fr Ophthalmol 2000; 23: 1057-1064.

8 Lee BL, Gutierrez P, Gordon M, Wilson MR, Cioffi GA, Ritch $\mathrm{R}$ et al. The glaucoma symptom scale. A brief index of glaucoma-specific symptoms. Arch Ophthalmol 1998; 116: 861-866.

9 Nelson P, Aspinall P, Papasouliotis O, Worton B, O'Brien C. Quality of life in glaucoma and its relationship with visual function. J Glaucoma 2003; 12: 139-150.

10 Laibovitz R, Boyle J, Snyder E, Strohmaier K, Adamsons I. Dorzolamide $v$ p pilocarpine as adjunctive therapies to timolol: a comparison of patient preference and impact on daily life. Clin Ther 1996; 18: 821-832.

11 Juniper EF. Interpreting of quality of life data. Qual Life Newslett 1999; 3.

12 Atkinson MJ, Stewart WC, Fain JM, Stewart JA, Dhawan R, Mozaffari E et al. A new measure of patient satisfaction with ocular hypotensive medications: The Treatment Satisfaction Survey-Intraocular Pressure (TSS-IOP). Health Qual Life Outcomes 2003; 1: 67.

13 Kass MA, Gordon M, Morley Jr RE, Meltzer DW, Goldberg JJ. Compliance with topical timolol treatment. Am J Ophthalmol 1997; 103: 188-193.

14 Kass MA, Meltzer DW, Gordon M, Cooper D, Goldberg JJ. Compliance with topical pilocarpine treatment. Am J Ophthalmol 1986; 101: 515-523. 
15 Granström PA. Glaucoma patients not compliant with their drug therapy: clinical and behavioral aspects. $\mathrm{Br} \mathrm{J}$ Ophthalmol 1982; 66: 464-470.

16 Stewart WC, Konstas AGP, Pfeiffer N. Patient and ophthalmologist attitudes concerning compliance and dosing in glaucoma treatment. J Ocular Pharmacol Ther 2004; 20: 461-469.

17 Kass MA, Gordon M, Meltzer DW. Can ophthalmologists correctly identify patients defaulting from pilocarpine treatment? Am J Ophthalmol 1986; 101: 524-530.

18 Alm A, Stjernschantz J, the Scandinavian Latanoprost Study Group. Effects on intraocular pressure and side effects of $0.005 \%$ latanoprost applied once daily, evening or morning: a comparison with timolol. Ophthalmology 1995; 102: 1743-1752.

19 Camras CB, the United States Latanoprost Study Group. Comparison of latanoprost and timolol in patients with ocular hypertension and glaucoma: a six-month, masked, multicenter trial in the United States. Ophthalmology 1996; 103: 138-147.

20 Watson P, Stjernschantz J, the Latanoprost Study Group. A six-month, randomized, double-masked study comparing latanoprost with timolol in open-angle glaucoma and ocular hypertension. Ophthalmology 1996; 103: 126-137.

21 Sherwood M, Brandt J, Bimatoprost Study Groups 1 and 2. Six-month comparison of bimatoprost once-daily and twice- daily with timolol twice-daily in patients with elevated intraocular pressure. Surv Ophthalmol 2001; 45: S361-S368.

22 Stewart WC, Kolker AE, Stewart JA, Leech JN, Jackson AL. Conjunctival hyperemia in healthy subjects after short-term dosing with latanoprost, bimatoprost, and travoprost. Am J Ophthalmol 2003; 135: 314-320.

23 Parrish RK, Palmberg P, Sheu WP, XLT Study Group. A comparison of latanoprost, bimatoprost, and travoprost in patients with elevated intraocular pressure: a 12-week, randomized, masked-evaluator multicenter study. $A m \mathrm{~J}$ Ophthalmol 2003; 135: 688-703.

24 Noecker RS, Dirks MS, Choplin NT, Bernstein P, Batoosingh AL, Whitcup SM, Bimatoprost/Latanoprost Study Group. A six-month randomized clinical trial comparing the intraocular pressure-lowering efficacy of bimatoprost and latanoprost in patients with ocular hypertension or glaucoma. Am J Ophthalmol 2003; 135: 55-63.

25 Netland PA, Landry T, Sullivan EK, Andrew R, Silver L, Weiner A et al. Travoprost Study Group. Travoprost compared with latanoprost and timolol in patients with open-angle glaucoma or ocular hypertension. Am J Ophthalmol 2001; 132: 472-484.

26 Stewart WC, Stewart JA, Jenkins JN, Jackson AL. Corneal punctate staining with latanoprost, bimatoprost, and travoprost in healthy subjects. J Glaucoma 2003; 12: $475-479$. 